LAWRENCE LIVERMORE N A TIO N A L LABORATORY

\title{
Report on 238Pu(n,x) surrogate cross section measurement
}

J. T. Burke, J. J. Ressler, R. A. Henderson, N. D. Scielzo, J. E. Escher, I. J. Thompson, J. Gostic, D. Bleuel, M. Weideking, L. A. Bernstein

April 2, 2010 
This document was prepared as an account of work sponsored by an agency of the United States government. Neither the United States government nor Lawrence Livermore National Security, LLC, nor any of their employees makes any warranty, expressed or implied, or assumes any legal liability or responsibility for the accuracy, completeness, or usefulness of any information, apparatus, product, or process disclosed, or represents that its use would not infringe privately owned rights. Reference herein to any specific commercial product, process, or service by trade name, trademark, manufacturer, or otherwise does not necessarily constitute or imply its endorsement, recommendation, or favoring by the United States government or Lawrence Livermore National Security, LLC. The views and opinions of authors expressed herein do not necessarily state or reflect those of the United States government or Lawrence Livermore National Security, LLC, and shall not be used for advertising or product endorsement purposes.

This work performed under the auspices of the U.S. Department of Energy by Lawrence Livermore National Laboratory under Contract DE-AC52-07NA27344. 


\title{
Report on ${ }^{238} \mathrm{Pu}(\mathrm{n}, \mathrm{x})$ surrogate cross section measurement
}

\author{
J.T. Burke, J.J. Ressler, R.A. Henderson, N.D. Scielzo, J.E. Escher, I.J. Thompson, \\ J. Gostic, D. Bleuel, M. Weideking, and L. A. Bernstein
}

\section{Objective:}

The goal of this year's effort is to measure the ${ }^{238} \mathrm{Pu}(\mathrm{n}, \mathrm{f})$ and ${ }^{238} \mathrm{Pu}(\mathrm{n}, 2 \mathrm{n})$ cross section from $100 \mathrm{keV}$ to $20 \mathrm{MeV}$. We designed a surrogate experiment that used the reaction ${ }^{239} \mathrm{Pu}\left(\alpha, \alpha^{\prime} \mathrm{x}\right)$ as a surrogate for ${ }^{238} \mathrm{Pu}(\mathrm{n}, \mathrm{x})$. The experiment was conducted using the STARS/LIBERACE experimental facility located at the 88 Inch Cyclotron at Lawrence Berkeley National Laboratory in January 2010. A description of the experiment and status of the data analysis follow.

\section{Design of experiment}

In order to obtain a reliable ${ }^{238} \mathrm{Pu}(\mathrm{n}, \mathrm{x})$ cross section we designed the experiment using the surrogate ratio technique. This technique allows one to measure a desired, unknown, cross section relative to a known cross section. In the present example, the ${ }^{238} \mathrm{Pu}(\mathrm{n}, \mathrm{x})$ cross section of interest is determined relative to the known ${ }^{235} \mathrm{U}(\mathrm{n}, \mathrm{x})$ cross section. To increase confidence in the results, and to reduce overall uncertainties, we are also determining the ${ }^{238} \mathrm{Pu}(\mathrm{n}, \mathrm{x})$ cross section relative to the known ${ }^{234} \mathrm{U}(\mathrm{n}, \mathrm{x})$ cross section. The compound nuclei of interest for this experiment were produced using inelastic alpha scattering. For example, ${ }^{236} \mathrm{U}\left(\alpha, \alpha{ }^{\prime} \mathrm{x}\right)$ served as a surrogate for ${ }^{235} \mathrm{U}(\mathrm{n}, \mathrm{x})$; analogous reactions were considered for the other cross sections. Surrogate experiments determine the probabilities for the decay of the compound nuclei into the various channels of interest (fission, gamma decay) by measuring particle-fission (p-f) or particle-gamma (p-g) reaction spectra. By comparing the decay probabilities associated with the unknown cross section to that of a known cross section it is possible to obtain the ratio of these cross sections and thus determine the unknown, desired cross section. For example the ${ }^{238} \mathrm{Pu}(\mathrm{n}, \mathrm{f})$ cross section will be determined by

$$
\sigma_{238 P u}(n, f)(E)=\frac{N_{p-f}\left({ }^{239} P u\left(\alpha, \alpha^{\prime}\right), E\right)}{N_{p-f}\left({ }^{236} U\left(\alpha, \alpha^{\prime}\right), E\right)} \times \sigma_{{ }^{235} U}(n, f)(E),
$$

where $\mathrm{N}_{\mathrm{p}-\mathrm{f}}\left({ }^{239} \mathrm{Pu}\left(\alpha, \alpha^{\prime}\right), \mathrm{E}\right)$ and $\mathrm{N}_{\mathrm{p}-\mathrm{f}}\left({ }^{236} \mathrm{U}\left(\alpha, \alpha^{\prime}\right), \mathrm{E}\right)$ is the number of ${ }^{239} \mathrm{Pu}$ and ${ }^{236} \mathrm{U}$ particle-fission coincidence events at a given energy and $\sigma^{235} \mathrm{U}(\mathrm{n}, \mathrm{f})(\mathrm{E})$ is the known energy dependent ${ }^{235} \mathrm{U}$ cross section.

\section{Electroplating cell}

A new electroplating cell was designed by J.T. Burke and R.A. Henderson for this experiment, shown in Fig. 1. The new electroplating cell allowed direct electroplating of actinide films onto thin carbon foils that were mounted on target frames. Due to the fragility of the very thin $C$ foils, and the need to have them perfectly centered on the target frame, it was necessary to have the foils premounted on the frame as opposed to the traditional method, which would be to electroplate the activity onto the foil prior to mounting the foil onto the frame. This new technique also limits the size of the target to the exact size needed and keep the target activity as low as possible. We can now electroplate to very specific areas on a 
prefabricated target frame for experiments. The design for this cell will be the subject of a brief Nuclear Instruments and Methods article to be submitted during the summer of 2010.
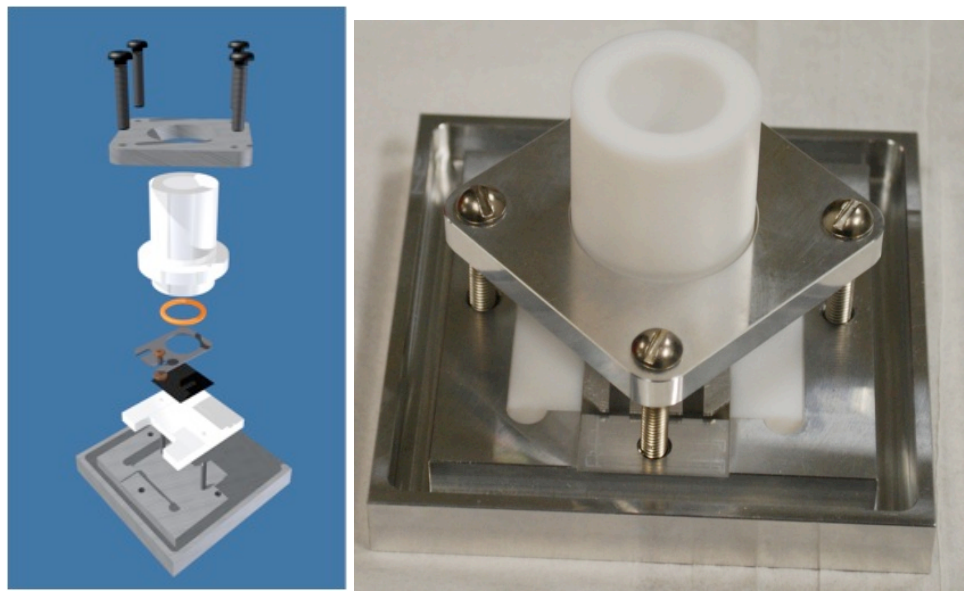

Figure 1. Electroplating cell CAD design and finished product. The electroplating cell was designed and fabricated within a two-week period at LLNL.

\section{Targets}

For this experiment, new actinide targets were fabricated by Roger

Henderson and Julie Gostic at LLNL. Three different actinide targets - ${ }^{235} \mathrm{U},{ }^{236} \mathrm{U}$ and ${ }^{239} \mathrm{Pu}$ - were electroplated onto $100 \mu \mathrm{g} / \mathrm{cm}^{2}$ carbon foils. All targets were alpha counted to establish their exact thickness, as shown in Fig. 2. The areal density of the ${ }^{235} \mathrm{U},{ }^{236} \mathrm{U}$ and ${ }^{239} \mathrm{Pu}$ targets were $416(5)$, of $322(2)$ and $140(1) \mu \mathrm{g} / \mathrm{cm}^{2}$, respectively. Minor contributions from neighboring isotopes were observed at low levels $\left(<1 \mu \mathrm{g} / \mathrm{cm}^{2}\right)$.

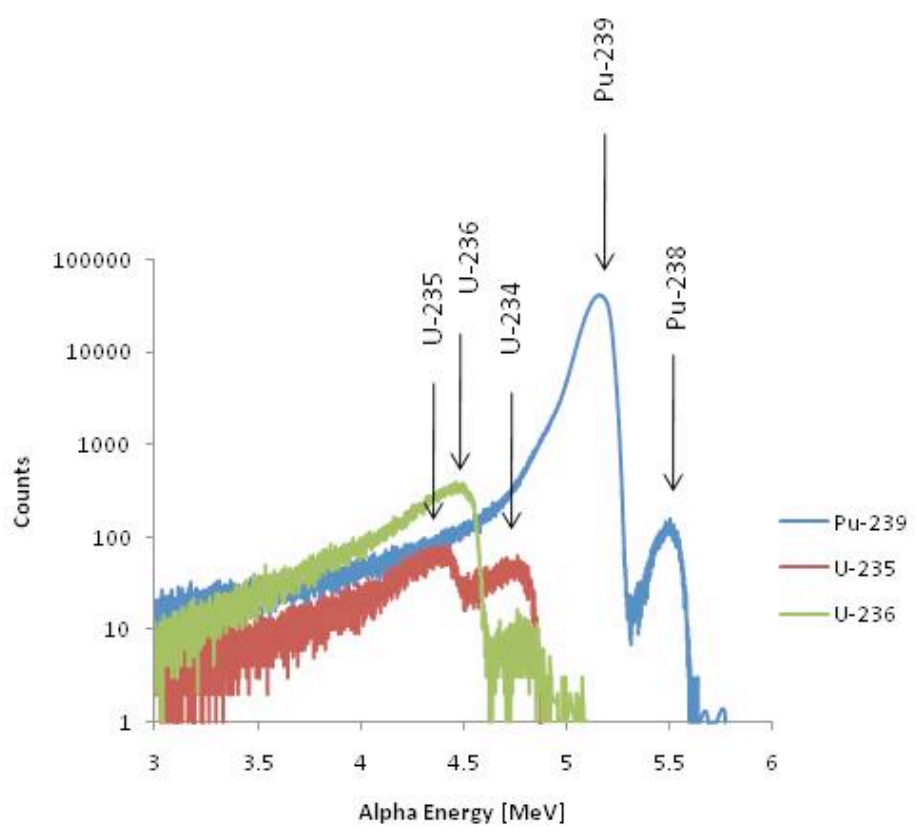


Figure 2. Alpha spectra from the ${ }^{239} \mathrm{Pu},{ }^{235} \mathrm{U}$, and ${ }^{236} \mathrm{U}$ targets were used to determine the target areal densities and also identify any contaminants present in the target. The counting periods for each target were 18.5 minutes, 9.3 hours, and 2.8 hours for the ${ }^{239} \mathrm{Pu},{ }^{235} \mathrm{U}$, and ${ }^{236} \mathrm{U}$ targets, respectively.

\section{Data Analysis}

In the two months that have passed since the experiment, a large amount of data analysis has been completed. The energy calibrations of the silicon detector elements (telescope and fission detector) have been completed and particle identification plots have been made; an example is shown in Fig. 3. The energy loss and recoil correction physics has been input into the analysis code and used to determine the true nuclear excitation energy. A small offset in the beam position from exact center has also been compensated for by including it in the physics of the recoil correction in the analysis code. The particle-fission timing spectrum has been generated and used to determine the prompt and random particle-fission spectra. The particle identification and ray-trace cuts have been made to define particles originating from the target (not scattered beam from collimation). Combining all above elements, the data sort code has been run to generate the preliminary particle-fission coincident spectra needed to obtain the fission cross section from all targets used during this experiment, as shown in Fig. 4. Hauser-Feshbach-type calculations have been carried out to provide preliminary tests of the ratio approach for the systems under consideration.

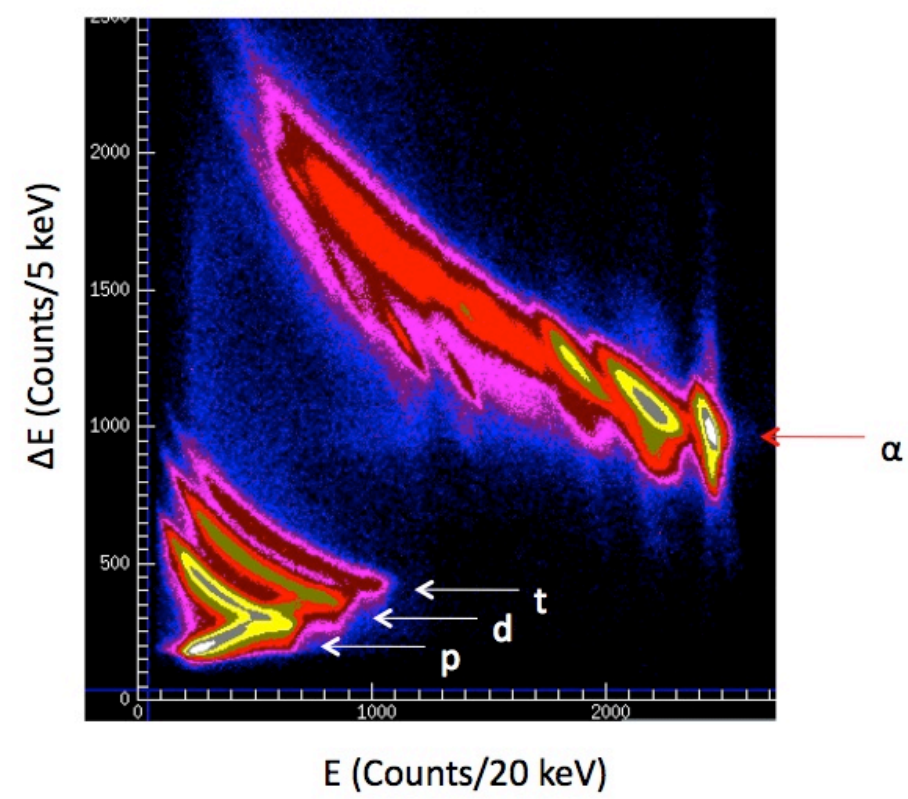

Figure 3. Particle identification plot for alphas on ${ }^{239} \mathrm{Pu}$. This plot is then used to select the scattered alpha particles and create an energy dependent particle-fission coincidence spectrum. Also shown are proton (p), deuteron (d) and triton (t) out channels. 


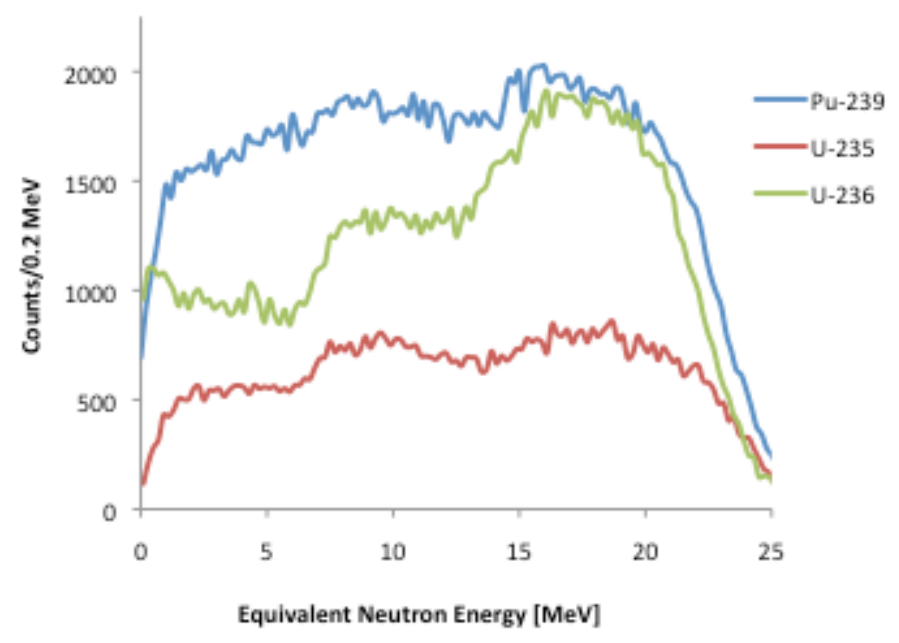

Figure 4. Particle-fission coincidence spectra for ${ }^{239} \mathrm{Pu},{ }^{235} \mathrm{U}$ and ${ }^{236} \mathrm{U}$ targets taken during the January 2010 experiment.

The statistics of the particle-fission spectrum should provide a statistical uncertainty of $5 \%$ or less for the inter-comparison of the fission cross sections.

\section{Work to complete}

We will continue to refine the data analysis of the fission cross-section and prepare the results for publication and for inclusion in the nuclear databases. We will also verify that the known cross section for ${ }^{235} \mathrm{U}(\mathrm{n}, \mathrm{f})$ and ${ }^{234} \mathrm{U}(\mathrm{n}, \mathrm{f})$ can be extracted correctly from the data. This will act as a check on the robustness of the technique and more specifically this particular experiment. We will then move on to the gamma ray analysis and reduce the data and extract the ${ }^{238} \mathrm{Pu}(\mathrm{n}, 2 \mathrm{n}) \mathrm{cross}$ section using the surrogate ratio technique for the $(n, 2 n)$ channel.

\section{Collaborators}

For this experiment, we collaborated with our colleagues, students and PostDocs from University of Richmond, the University of California Berkeley, and Lawrence Berkeley National Laboratory. 